\title{
Ex Vivo Reconstitution of Arterial Endothelium by Embryonic Stem Cell-Derived Endothelial Progenitor Cells in Baboons
}

\author{
Qiang Shi, Vida Hodara, ${ }^{2}$ Calvin R. Simerly, ${ }^{3}$ Gerald P. Schatten, ${ }^{3}$ and John L. VandeBerg ${ }^{1}$
}

There is an increasing need for an animal model that can be used to translate basic research into clinical therapy. We documented the differentiation and functional competence of embryonic stem cell (ESC)-derived endothelial cells in baboons. Baboon angioblasts were sequentially differentiated from embryoid body cultures for 9 days in an angioblast differentiation medium with varying concentrations of BMP-4, FLT-3 ligand, stem cell factor, thrombopoietin, basic fibroblast growth factor (FGF), vascular endothelial growth factor (VEGF), and knockout serum replacement. Real-time polymerase chain reaction results showed that ESC-derived angioblasts downregulated NANOG and OCT3/4, upregulated T-brachyury and GATA2, and moderately expressed CD34; they did not express CD144, TEK, or VWF, and varied in levels of CD31 expression. Several populations of putative angioblasts appeared 3 days and 9 days after differentiation, as identified by flow cytometry. Angioblasts at this stage exhibited dual paths of differentiation toward hematopoietic and vascular fates. To examine whether derived angioblasts could reconstitute the endothelium, we built an ex vivo culture system and seeded fluorescently labeled angioblast cultures onto a denuded segment of the femoral artery. We found that the seeded cells were able to grow into the endothelium on the interior surface of denuded artery segments within 5 days after seeding. After 14 days of ex vivo culture, the transplanted cells expressed CD31, an endothelial marker. The control arteries, seeded with vehicle only, did not harbor cells with endothelial markers. We conclude that ESCderived angioblasts are promising therapeutic agents for repairing damaged vasculature, and that the baboon model will be vital for optimizing therapies for human clinical studies.

\section{Introduction}

$\mathrm{T}_{\mathrm{s}}$ HE ENDOTHELIUM CONTRIBUtes considerably to the pathogenesis of cardiovascular disease (CVD). It is progressively impaired with age, and the supply of tissue reparative cells at an advanced age is insufficient to repair the damage [1,2]. Although therapeutic developments have improved the prognosis for people with CVD, mortality rates have nevertheless remained virtually unchanged in the last 20 years [3-5]. Therefore, there is a need for novel alternative therapies. Embryonic stem cells (ESCs) are pluripotent and are able to differentiate into progenitors; they have the potential to regenerate vascular cells and to replace damaged tissues [6-8].

After more than a decade of research with human and mouse ESCs, there is an increasing recognition of the need for nonhuman primate models for stem cell research and applications [9-13]. With regard to cell-based therapy, stem cell turnover is remarkably higher in small animals than in large ones [14]. That could cause fundamental differences in the stemness profile of therapeutic agents and in the signal- ing pathways that regulate the fate of ESCs [13]. In addition, the modes of stem cell delivery (dosage, time points, methods) have a profound effect on the efficacy of treatment. Applying the methods for stem cell delivery and treatment developed in small animal models to human subjects is usually problematic $[15,16]$. There is also a lack of thorough documentation, especially in a biologically relevant animal model, of cell migration and trafficking to nontarget site(s) and uncontrolled cell proliferation when derived cells are transplanted into subjects. More recently, there has been an increasing awareness that the potency of ESC-derived cells must improve to reach their therapeutic efficacy because we still have not recognized those stem cell derivatives that exert reparative functions like their counterparts as mobilized by the physical insults $[17,18]$. Given the similarities between humans and baboons, ESC-derivatives developed from the baboon can be more informative to us about the biology of stem cells in human beings, which facilitates the use of stem cells for clinical applications and optimizes therapies before they are advanced to human clinical studies.

\footnotetext{
${ }^{1}$ Southwest National Primate Research Center, Texas Biomedical Research Institute, San Antonio, Texas.

${ }^{2}$ Virology and Immunology Department, Texas Biomedical Research Institute, San Antonio, Texas.

${ }^{3}$ Pittsburgh Development Center, University of Pittsburgh School of Medicine, Pittsburgh, Pennsylvania.
} 
This investigation develops a new approach for generating angioblasts for stem cell therapy and tests the functional competence of endothelium produced from ESCs. We have also established a novel bioassay that allows us to evaluate whether ESC-derived angioblasts have therapeutic effects. The mechanisms underlying this bioassay are based on the fact that microenvironments are vital elements that regulate and promote stem cell differentiation and functioning [1925]; therapeutic cells cannot be identified based solely on their phenotypic markers, but must depend, in part, on their interactions with correct residing environments. Since we seed ESC-derived cells directly in targeted tissue, it enables us to observe direct interactions between candidate-derived cells and their target-damaged tissues; consequently, we can determine what characteristics and which maturation stage give rise to the higher reparative function.

Our results suggest that this approach provides a novel method to validate whether differentiated cells are able to integrate into adult tissue and to function as cell agents. ESCbased therapy has great potential for clinical applications, but optimal clinical benefit cannot be achieved without a good understanding of which cells should be transplanted. Our model can be an important bridge to bringing regenerative medicine a step closer from bench to bedside.

\section{Materials and Methods}

\section{Cell culture}

Fully characterized baboon ESCs were obtained from the Pittsburgh Development Center, University of Pittsburgh School of Medicine [15,26,27]. The BAB15 baboon ESC line at passage 39 was used in this study. They were cultured according to the published method and used within no more than 10 passages [28]. Undifferentiated ESCs were maintained with feeder cells in the ESC medium containing 15\% knockout serum replacement; $1 \%$ nonessential amino acids $(100 \times) ; 1 \%$ L-glutamine $(100 \times) ; 1 \%$ antibiotic-antimycotic $(100 \times) ; 100 \mu \mathrm{M} \beta$-mercaptoethanol; and $12 \mathrm{ng} / \mathrm{mL}$ human basic fibroblast growth factor (FGF) in knockout Dulbecco modified Eagle's minimal essential medium (DMEM). Endothelial cells (ECs) from an adult blood vessel were isolated and cultured according to the method described previously as a reference control [29].

\section{In vitro differentiation}

Our protocol for differentiating angioblasts from ESCs was modified based on reported methods [30-33]. We derived angioblasts from ESCs in 3-dimensional embryoid body (EB) culture in the angioblast differentiation medium (ADM). We used AggreWell plates to form uniform EBs containing about 5,000-10,000 cells and cultured them in the ESC medium for 3 days. The ADM consisted of the ESC medium supplemented with a cocktail of $0.5 \mathrm{ng} / \mathrm{mL}$ BMP- $4,5 \mathrm{ng} / \mathrm{mL}$ basic FGF, $10 \mathrm{ng} / \mathrm{mL}$ vascular endothelial growth factor (VEGF), $5 \mathrm{ng} / \mathrm{mL}$ stem cell factor, $5 \mathrm{ng} / \mathrm{mL}$ thrombopoietin, and $10 \mathrm{ng} / \mathrm{mL}$ FLT-3 ligand. Subsequently, we added ADM to EB cultures at gradually increased ratios at the time points indicated in Fig. 1. All cell cultures were fed with a fresh medium every day during the differentiation process. Samples were taken during EB culture for gene expression profiling and flow cytometry. At the end of day 9, EBs were transferred and cultured on colla- gen-coated plates for monolayer culture by the modified ADM, in which knockout serum replacement was replaced with an equal amount of fetal calf serum. We harvested specified angioblasts by enzymatic digestion after 12 days in culture to test their reconstitutive ability.

\section{Gene expression by real-time polymerase chain reaction}

Total RNA was extracted from EC control cells, and undifferentiated ESCs, and differentiated cells at days 5 and 9 using the RNeasy Plus Mini Kit. The probes used for real time-polymerase chain reaction (RT-PCR) are listed in Table 1. Quantitative RT-PCR was performed in $25 \mu \mathrm{L}$ of reaction mix containing $1 \times$ SYBR $^{\circledR}$ Green PCR master mix and 200 $\mathrm{nM}$ each of forward and reverse primers, template cDNA, and a housekeeping gene (GAPDH) as an internal control; then stopped at 40 cycles (temperature program: $2 \mathrm{~min}$ at $50^{\circ} \mathrm{C}, 10 \mathrm{~min}$ at $95^{\circ} \mathrm{C}, 40$ cycles of $15 \mathrm{~s}$ each at $95^{\circ} \mathrm{C}, 1 \mathrm{~min}$ at $60^{\circ} \mathrm{C}$ ). Transcripts were amplified on a $7900 \mathrm{HT}$ PCR System. Results were expressed by cycle threshold $(\mathrm{Ct})$ values. Three independent experiments were conducted.

\section{Flow cytometry}

Single-cell suspensions from EBs were prepared by 1:1 trypsin:collagenase digestion for $30 \mathrm{~min}$. After the cells were washed with cold phosphate-buffered saline (PBS) and blocked by $1 \%$ human $A B$ serum in $\mathrm{PBS}$, they were stained with fluorescently conjugated antibodies for flow cytometry at $4^{\circ} \mathrm{C}$ for 20 $30 \mathrm{~min}$. Table 2 lists vendors, clones, and antibody dilutions. UEA-1 conjugated with fluorescein isothiocyanate (Sigma) was used at $5 \mu \mathrm{L} / 10^{6}$ cells. Undifferentiated ESCs served as controls for monitoring angioblast differentiation. Isotype-matched control antibody staining was performed using the same cells to determine background fluorescence and for data processing. Flow cytometry was performed on a Cyan (Dako). All flow cytometry procedures were repeated at least 3 times.

\section{Long-term tracing of labeled cells}

To trace the transplanted cells in ex vivo culture, we labeled the cells with the fluorescent CellTracker probe, CMRA (Invitrogen), according to the manufacturer's instructions, by replacing the culture medium with a fresh medium (containing $10 \mu \mathrm{M}$ of CMRA) and incubating for $45 \mathrm{~min}$.

\section{Construction of ex vivo bioreactor}

Figure 4 shows the prototype of the ex vivo system that was established in our laboratory. The bioreactor has 2 parts: a rotary cylinder [Fig. $4 \mathrm{~A}(\mathrm{a})$ ] with 4 stainless steel tubes on both sides [Fig. 4A(b)], and a laminar perfusion system driven [Fig. 4A(c)] by a digital peristaltic pump. A segment of baboon femoral artery 5-7-cm long and without any branches or holes on the wall was treated with $0.05 \%$ trypsin together with $0.1 \%$ collagenase and $0.1 \%$ DNase I for $30 \mathrm{~min}$ at $37^{\circ} \mathrm{C}$ to remove the endothelium. After thoroughly washing the segment with a medium to detach all ECs, we seeded the transplanted cells onto the lumen of the denuded artery and used plastic tubing to ligate the 2 ends of the vessel segment to the steel tubes in the bioreactor to construct a circuit. The endothelial culture medium (EGM-2, Lonza) in a reservoir [Fig. $4 \mathrm{~A}(\mathrm{~d})$ ] was perfused through the 
Table 1. Primers for Quantitative Real Time-Polymerase Chain Reaction

\begin{tabular}{|c|c|c|c|c|}
\hline PrimerBank ID & Gene & Sequences & Length & $\mathrm{Tm}$ \\
\hline \multirow[t]{2}{*}{$19743811 b 1$} & \multirow[t]{2}{*}{ T-brachyury } & Forward primer TATGAGCCTCGAATCCACATAGT $\left(5^{\prime} \rightarrow 3^{\prime}\right)$ & 23 & 60.4 \\
\hline & & Reverse primer CCTCGTTCTGATAAGCAGTCAC & 22 & 60.4 \\
\hline \multirow[t]{2}{*}{$68342037 \mathrm{~b} 1$} & \multirow[t]{2}{*}{ CD34 } & Forward primer TACCCTTGGAAGTACCAGCCT $\left(5^{\prime} \rightarrow 3^{\prime}\right)$ & 21 & 62.0 \\
\hline & & Reverse primer GTTTCTGTGATGTTTGTTGTGGC & 23 & 61.0 \\
\hline \multirow[t]{2}{*}{$166362712 b 1$} & \multirow[t]{2}{*}{ cadherin 5 , type 2} & Forward primer TTGGAACCAGATGCACATTGAT $\left(5^{\prime} \rightarrow 3^{\prime}\right)$ & 22 & 60.2 \\
\hline & & Reverse primer TCTTGCGACTCACGCTTGAC & 20 & 62.7 \\
\hline \multirow[t]{2}{*}{ 224611700b1 } & \multirow[t]{2}{*}{ GATA2 } & Forward primer GCAACCCCTACTATGCCAACC $\left(5^{\prime} \rightarrow 3^{\prime}\right)$ & 21 & 62.8 \\
\hline & & Reverse primer CAGTGGCGTCTTGGAGAAG & 19 & 60.1 \\
\hline \multirow[t]{2}{*}{$195546779 b 1$} & \multirow[t]{2}{*}{ KDR } & Forward primer GGCCCAATAATCAGAGTGGCA $\left(5^{\prime} \rightarrow 3^{\prime}\right)$ & 21 & 62.2 \\
\hline & & Reverse primer CCAGTGTCATTTCCGATCACTTT & 23 & 60.8 \\
\hline \multirow[t]{2}{*}{$153945815 b 1$} & \multirow[t]{2}{*}{ NANOG } & Forward primer TTTGTGGGCCTGAAGAAAACT $\left(5^{\prime} \rightarrow 3^{\prime}\right)$ & 21 & 60.0 \\
\hline & & Reverse primer AGGGCTGTCCTGAATAAGCAG & 21 & 61.6 \\
\hline \multirow[t]{2}{*}{$110347450 \mathrm{~b} 1$} & \multirow[t]{2}{*}{ PECAM-1 } & Forward primer AACAGTGTTGACATGAAGAGCC $\left(5^{\prime} \rightarrow 3^{\prime}\right)$ & 22 & 60.8 \\
\hline & & Reverse primer TGTAAAACAGCACGTCATCCTT & 22 & 60.2 \\
\hline \multirow[t]{2}{*}{$113722115 b 1$} & \multirow[t]{2}{*}{ PLXNA2 } & Forward primer CTGAGAATCGTGACTGGACCT $\left(5^{\prime} \rightarrow 3^{\prime}\right)$ & 21 & 60.9 \\
\hline & & Reverse primer GCTTATAGACCCGGTTGATGG & 21 & 60.0 \\
\hline \multirow[t]{2}{*}{$183396798 b 1$} & \multirow[t]{2}{*}{ TEK } & Forward primer TTAGCCAGCTTAGTTCTCTGTGG $\left(5^{\prime} \rightarrow 3^{\prime}\right)$ & 23 & 61.6 \\
\hline & & Reverse primer AGCATCAGATACAAGAGGTAGGG & 23 & 60.7 \\
\hline \multirow[t]{2}{*}{$89191867 b 1$} & \multirow[t]{2}{*}{ VWF } & Forward primer CCGATGCAGCCTTTTCGGA $\left(5^{\prime} \rightarrow 3^{\prime}\right)$ & 19 & 62.7 \\
\hline & & Reverse primer TCTGGAAGTCCCCAATAATCGAG & 23 & 61.2 \\
\hline \multirow[t]{2}{*}{ 83641890b1 } & \multirow[t]{2}{*}{ GAPDH } & Forward primer AAGGTGAAGGTCGGAGTCAAC $\left(5^{\prime} \rightarrow 3^{\prime}\right)$ & 21 & 61.7 \\
\hline & & Reverse primer GGGGTCATTGATGGCAACAATA & 22 & 60.6 \\
\hline
\end{tabular}

Tm, melting temperature.

lumen of the vessel. The whole vessel was submerged in $10 \%$ fetal bovine serum F-12K medium and placed in an incubator. Figure $4 \mathrm{~B}$ is a photograph of ex vivo bioreactor.

In most instances, 2 arterial segments were harvested from the same animal and denuded under the same conditions, then cells were labeled using CellTracker as stated above. The treatment group received a cell suspension $\left(2-5 \times 10^{5}\right)$ of ESCderived progenitors in $2 \mathrm{~mL}$ of the endothelial medium, injected into the lumen of 1 denuded arterial segment; the control group received $2 \mathrm{~mL}$ of medium without cells, injected into a second denuded arterial segment from the same baboon. Then, we rotated the rotary cylinder of the bioreactor $90^{\circ}$ every hour for $5 \mathrm{~h}$ to promote cell attachment to the extracellular matrix. Finally, we perfused the vessel at a lower flow rate of
$0.5 \mathrm{~mL} / \mathrm{min}$ for the first $10 \mathrm{~h}$ followed by $2 \mathrm{~mL} / \mathrm{min}$ for the rest of the culture period to nourish the seeded cells.

\section{Immunofluorescence and whole-mount immunostaining}

Cells were seeded on either BioCoat chamber slides or cover slips for immunostaining; single cells from EBs were prepared by $1: 1$ trypsin/collagenase digestion for $20-30 \mathrm{~min}$ at $37^{\circ} \mathrm{C}$ and cytospun onto the slides. They were fixed in $2 \%$ or $4 \%$ paraformaldehyde (PFA) in PBS at room temperature for $20 \mathrm{~min}$, then washed twice with $1 \mathrm{~mL}$ of PBS for $5 \mathrm{~min}$, and blocked for $45 \mathrm{~min}$ with $0.5 \mathrm{~mL}$ of $1 \%$ bovine serum albumin (BSA), $10 \%$ normal donkey serum, and $0.1 \%$ Triton X-100 in the Hank's

Table 2. Antibodies Used for Flow Cytometry

\begin{tabular}{lllr}
\hline Antibodies & Vendors and catalog No. & Clone or source & Amount or dilution \\
\hline CD31-Cy5 & BioLegend no. 303112 & WM59 & $5 \mu \mathrm{L} / 10^{6} \mathrm{cells}$ \\
CD34-PE & BD Biosciences no. 550619 & 563 & $10 \mu \mathrm{L} / 10^{6} \mathrm{cells}$ \\
CD31-FITC & BD Biosciences no. 557508 & $5 \mu \mathrm{L} / 10^{6} \mathrm{cells}$ \\
CD117-APC & BD Biosciences no. 550412 & WM59 & $5 \mu \mathrm{L} / 10^{6} \mathrm{cells}$ \\
CD45-PerCP & BD Biosciences no. 558411 & YB5.B8 & $5 \mu \mathrm{L} / 10^{6} \mathrm{cells}$ \\
CXCR4-APC & BioLegend no. 306510 & DO58-1283 & $5 \mu \mathrm{L} / 10^{6} \mathrm{cells}$ \\
VEGFR3-PE & R\&D Systems no. FAB3492P & 12 G5 & $5 \mu \mathrm{L} / 10^{6} \mathrm{cells}$ \\
T-brachyury & R\&D Systems no. AF-2085 & 54733 & $1: 100$ \\
GATA2 & R\&D Systems no. AF2046 & Goat & $1: 100$ \\
KDR & R\&D Systems no. AF357 & Goat & $1: 100$ \\
$\alpha$-actin & Sigma no. F3337 & Goat & $1: 50$ \\
CD235a & Abcam no. ab35032 & $1 \mathrm{~A} 4$ & $1: 100$ \\
OCT3/4 & R\&D Systems no. AF1759 & Rabbit & $1: 200$ \\
NANOG & R\&D Systems no. AF1997 & Goat & $1: 200$ \\
SSEA-4 & R\&D Systems no. FAB1435F & Goat & MC-813-70 \\
Anti-goat & Santa Cruz no. sc-45106 & Donkey & cells \\
Anti-rabbit & Santa Cruz no. sc-45102 & Donkey & 1,000 \\
\hline
\end{tabular}




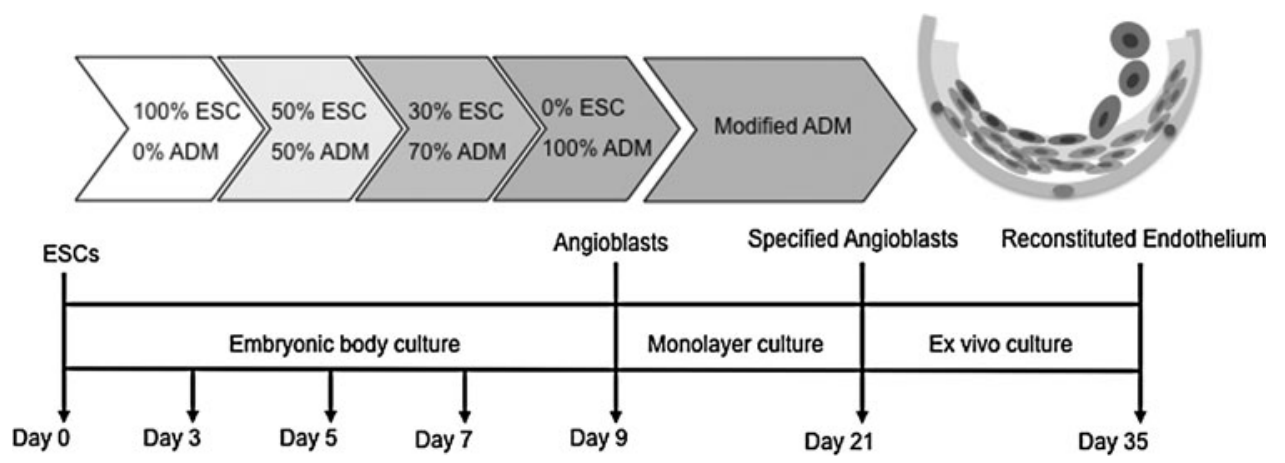

FIG. 1. Experimental design for generating angioblasts from ESCs. Undifferentiated ESCs were cultured with feeder cells under routine conditions. The embryoid body (EB) method was used to generate angioblasts from ESCs. After EBs were formed, they were suspended in ESC/ADM media with varying ratios for indicated times. At the end of angioblast induction, they were transferred to collagen-coated plates to reach confluence. The reconstitutive ability of derived cells was evaluated by an ex vivo culture system. (Endothelial cells, inner layer; smooth muscle cells, intermediate layer cells; fibroblasts and pericyte, outer layer cells). ESCs, embryonic stem cells; ADM, angioblast differentiation medium.

buffer $\mathrm{pH}$ 7.2-7.4. The slides were incubated with a primary antibody (see Table 2) in 1\% BSA and 10\% normal donkey serum in the Hank's buffer at $4^{\circ} \mathrm{C}$ overnight. The next day they were washed in 1\% BSA in the Hank's buffer 3 times. The secondary antibody was diluted according to the manufacturer's instructions in 1\% BSA in the Hank's buffer, $\mathrm{pH} 7.2$ 7.4 , for $60 \mathrm{~min}$ at room temperature in the dark. Cells were washed 3 times with 1\% BSA in the Hank's buffer. Slides were covered with an antifade mounting solution and viewed with a Nikon Eclipse E800 fluorescence microscope. Arterial tissues with and without cell transplantation were embedded in optimal cutting temperature compound (OCT) in a cryomold and overlaid with OCT. The samples were quickly frozen on dry ice; $5-10-\mu \mathrm{m}$ sections were cut on a superfrost slide and fixed in $2 \%$ PFA at room temperature for $20 \mathrm{~min}$. We processed the sections immediately with immunofluorescence staining as described above.

\section{Scanning electron microscopy}

Tissue samples were washed 3 times with PBS and immediately fixed in $4 \%$ formaldehyde $/ 1 \%$ glutaraldehyde for further processing. Images were taken using the LEO 435VP scanning electronic microscope.

FIG. 2. Characteristics of pluripotent baboon stem cells. Pluripotency of baboon ESCs was confirmed by growth behavior in colonies [(a) $100 \times$ ] and positive immunostaining for NANOG [(b) $200 \times$ ], OCT-4 [(c) $200 \times$ ], SSEA-4 [(d) $400 \times$ ], and histochemical staining for alkaline phosphatase [(e) $100 \times$ ]. (f) was isotype image $(200 \times)$.

\section{Results}

In this study, we developed a protocol to generate angioblast cultures from baboon ESCs, characterized their biological features, and evaluated whether they could repair a damaged arterial endothelium by determining the growth of derived angioblasts on a denuded vessel surface. Figure 1 is an outline of our experimental design.

\section{Characteristics of pluripotent baboon ESCs}

We evaluated the pluripotency of undifferentiated ESCs based on previously reported methods [15,26-27]. Typical ESC colonies were seen after regular passaging with feeder cells (Fig. 2a). These cells also expressed pluripotency markers, such as nuclear NANOG (Fig. 2b), nuclear OCT-4 (Fig. 2c), and membrane SSEA-4 (Fig. 2d) and showed positive staining for alkaline phosphatase (Fig. 2e).

\section{Differentiation of angioblasts from ESCs by EB culture}

We differentiated ESCs toward angioblasts in the form of embryonic bodies according to the design shown in Fig. 1; we
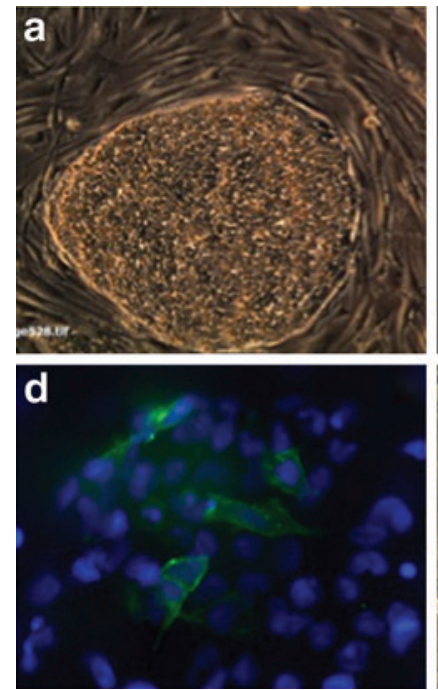
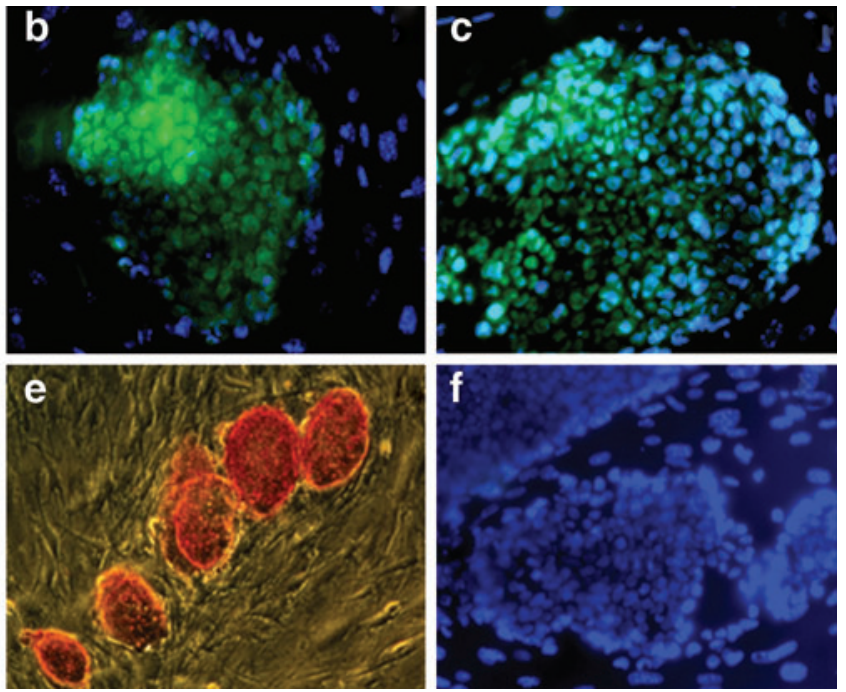

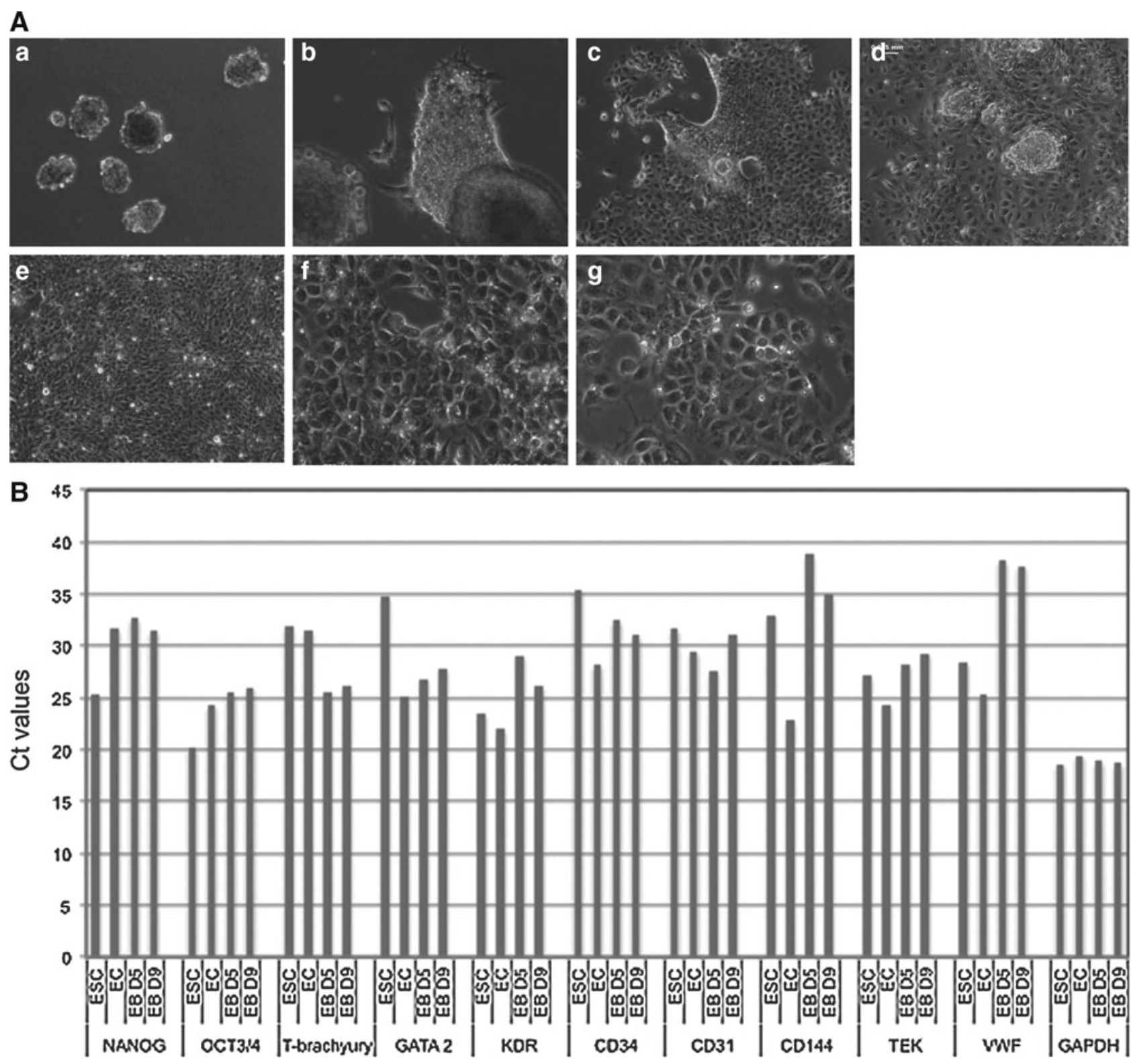

FIG. 3. Angioblast formation from EBs under ADM culturing. (A) Morphological development of angioblasts under ADM culturing. Undifferentiated ESCs were induced to form EBs using AggreWellÔ plates; 5,000-10,000 cells were contained in each EB (a). After 9 days of culture in ESC/ADM media at various ratios as indicated Fig. 1, EBs were transferred onto collagen-coated plates and their morphological changes during differentiation were observed. Images (b) through (g) are representative of their growth features. One day after initiation of the monolayer culture (b), some cells grew out from EBs and continued to cover the plate after 3 days (c) and 5 days (d); the cultures became confluent after 9 days (e). Angioblast cultures appeared to have typical cobblestone morphology under phase-contrast microscopy from day 5 (f) and retained that morphology for 3 weeks (g). (a-e), 100×. (f-g) $400 \times$. (B) Gene expression analysis by real timepolymerase chain reaction (RT-PCR) of EB cultures grown in ADM for 5 and 9 days. Total RNA was isolated from ESC, EC, and EB cultures at day 5 (D5) and day 9 (D9). Expression of 10 angioblast marker genes, together with a housekeeping gene (GAPDH) was analyzed by quantitative real-time PCR. All mRNA expression levels are expressed as cycle threshold values. (C) Immunohistochemical staining of mesodermal nuclear transcription factors T-brachyury and GATA2, and membrane KDR in ESCs $(\mathbf{a}-\mathbf{c})$ and EBs at day 5 (d-f). (g), isotype control. Nuclei are stained blue with DAPI. 400 $\times$. (D) The kinetics of generation of angioblasts during culture of EBs in ADM. Flow cytometry results indicate the characteristics of phenotypic expression of several progenitor markers in pluripotent ESCs (a, d, g), in ESC-derived cells after 3 days differentiation (b, e, h), and in ESC-derived cells after 9 days differentiation (c, $\mathbf{f}, \mathbf{i})$. (E) Dual differentiation of angioblasts toward hematopoietic and vascular lineages. When angioblasts were cultured in monolayer, a mixed culture of suspended cells and attached cells (a) appeared 1-2 days after cell seeding. Some cells spontaneously formed vascular structures consisting of lumen and capillary (b). After 5-7 days, we observed cell clusters with a red grape-shape (c); immunohistochemical staining confirmed the presence of CD235a [(f), red], an early erythrocyte marker. Spindle-shaped colony cells also existed (d); some of them were positively stained for smooth muscle $\alpha$-actin [(g), green], either in assembled fiber form or unassembled premature molecules. Distinct cobblestone-shaped cultures were also observed (e); they were strongly positive for CD34 [(h), red]. All cell nuclei were stained with DAPI (blue). Isotype-matched staining is shown in (i). (a-e), $100 \times$. (f-i), $400 \times$. EC, endothelial cell; DAPI, 4,6-diamidino-2-phenylindole. 


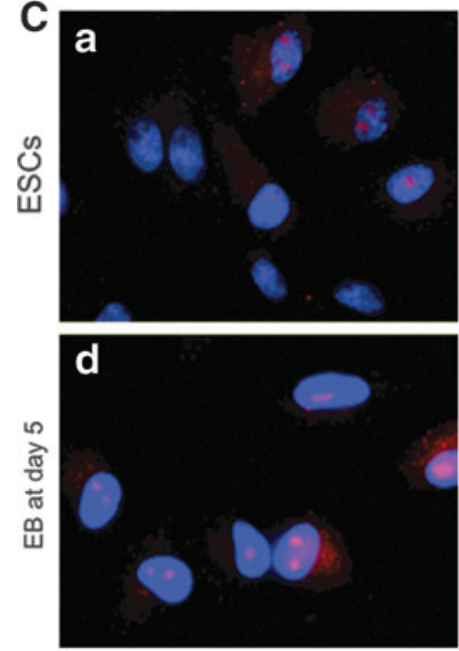

T-brachyury
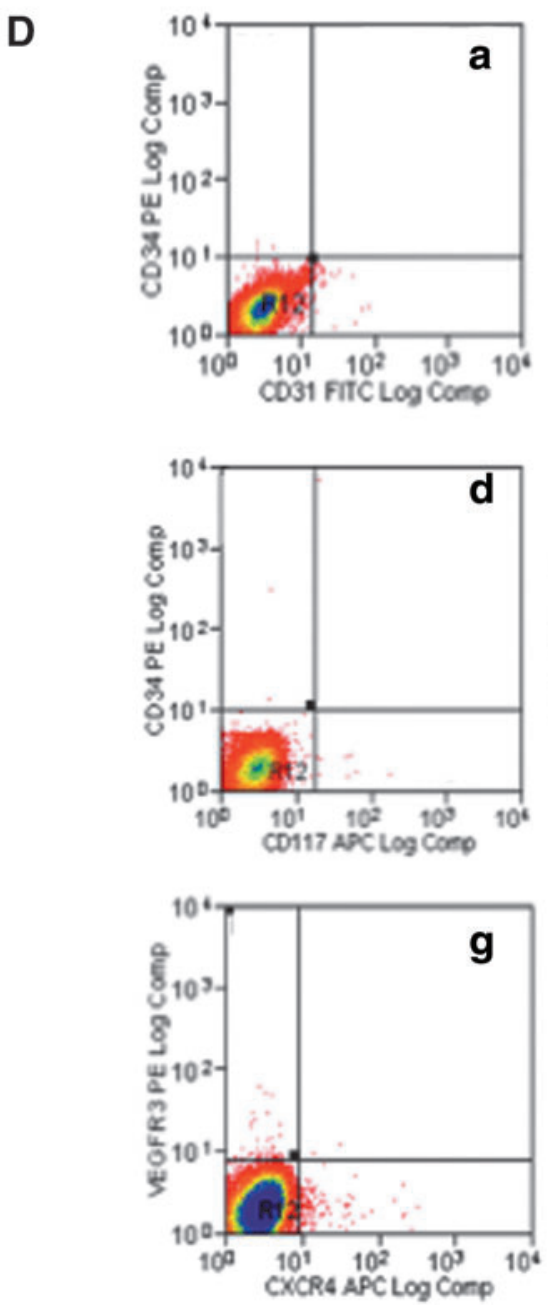
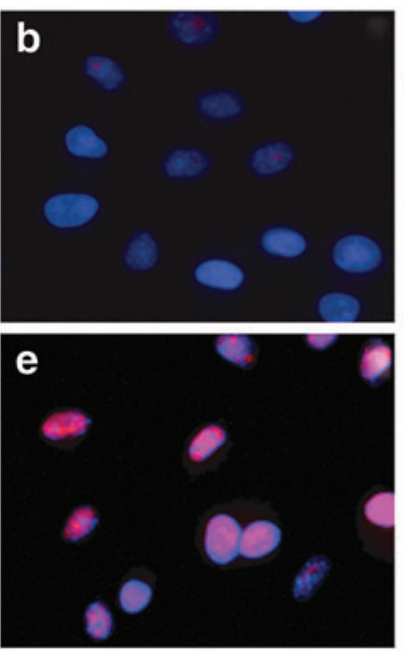

GATA2
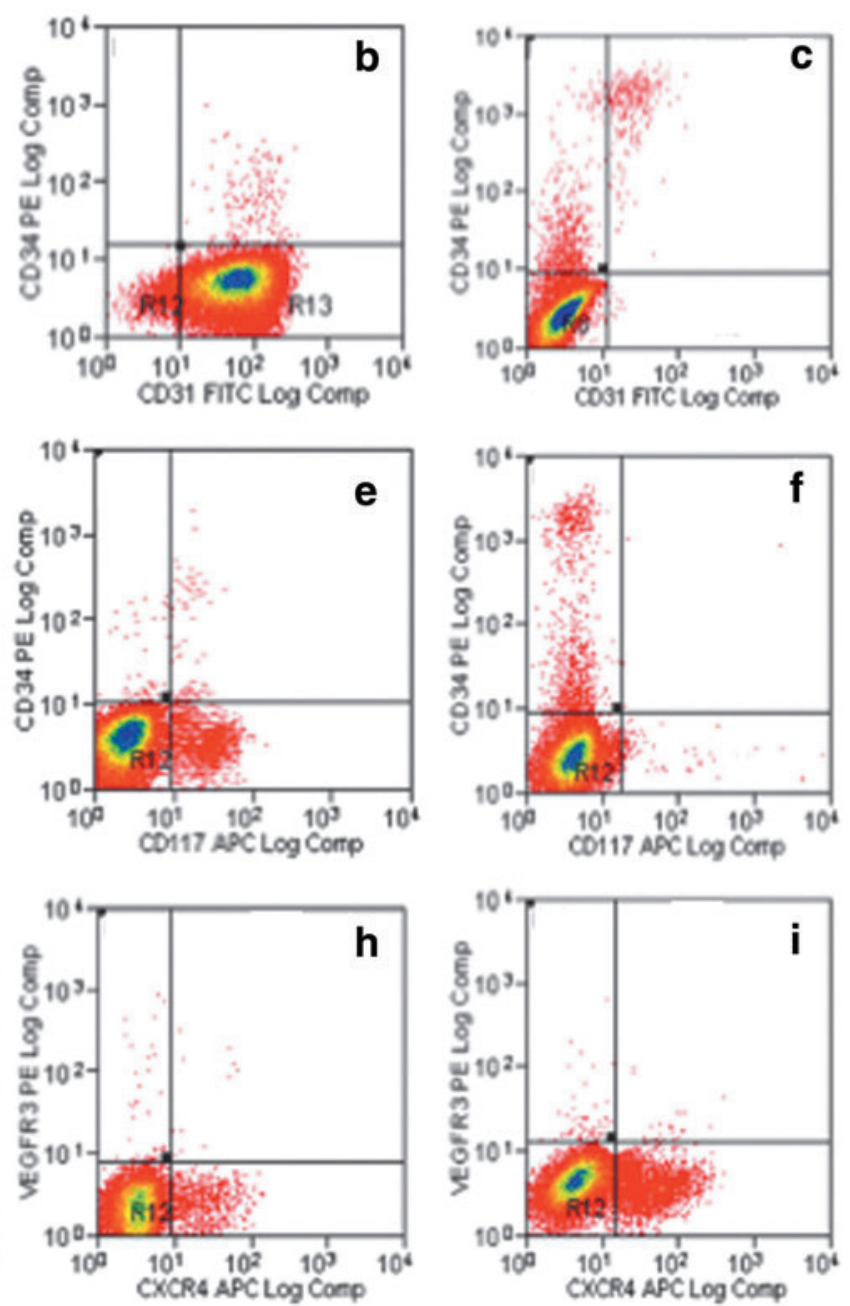
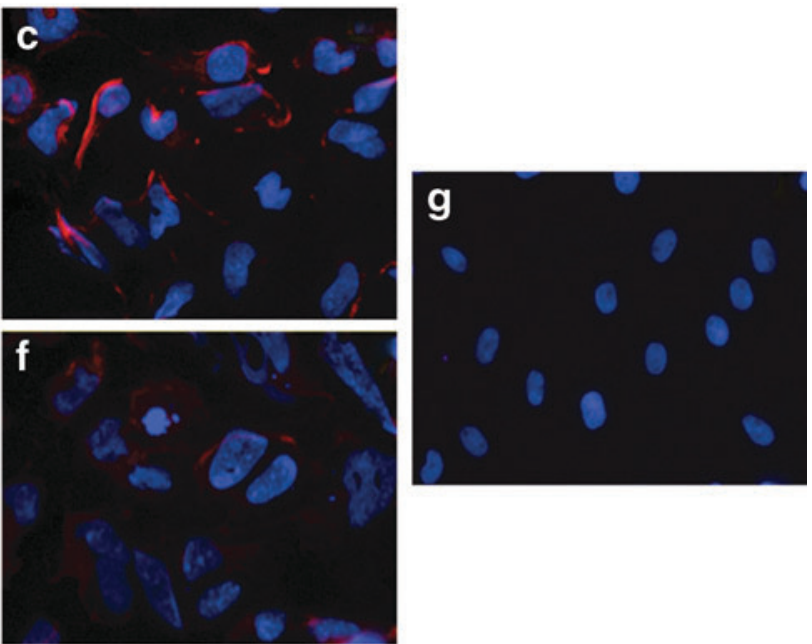

KDR

FIG. 3. (Continued)

transferred the EBs onto collagen IV-coated plates at day 9 and cultured in monolayer for 12 days in the presence of angiogenic growth factors; during this period, we documented their growth behaviors morphologically under phase-contrast microscopy, as indicated in Fig. 3A. Figure 3A(a) shows EBs be- fore seeding; 1 day after seeding, we observed that some cells migrated from EBs aggressively, proliferated in the monolayer within 3-5 days, and became confluent after 9 days [Fig. 3A(be)]. Angioblasts cultured under such conditions dominantly had a typical cobblestone shape [Fig. 3A(f, g)]. 

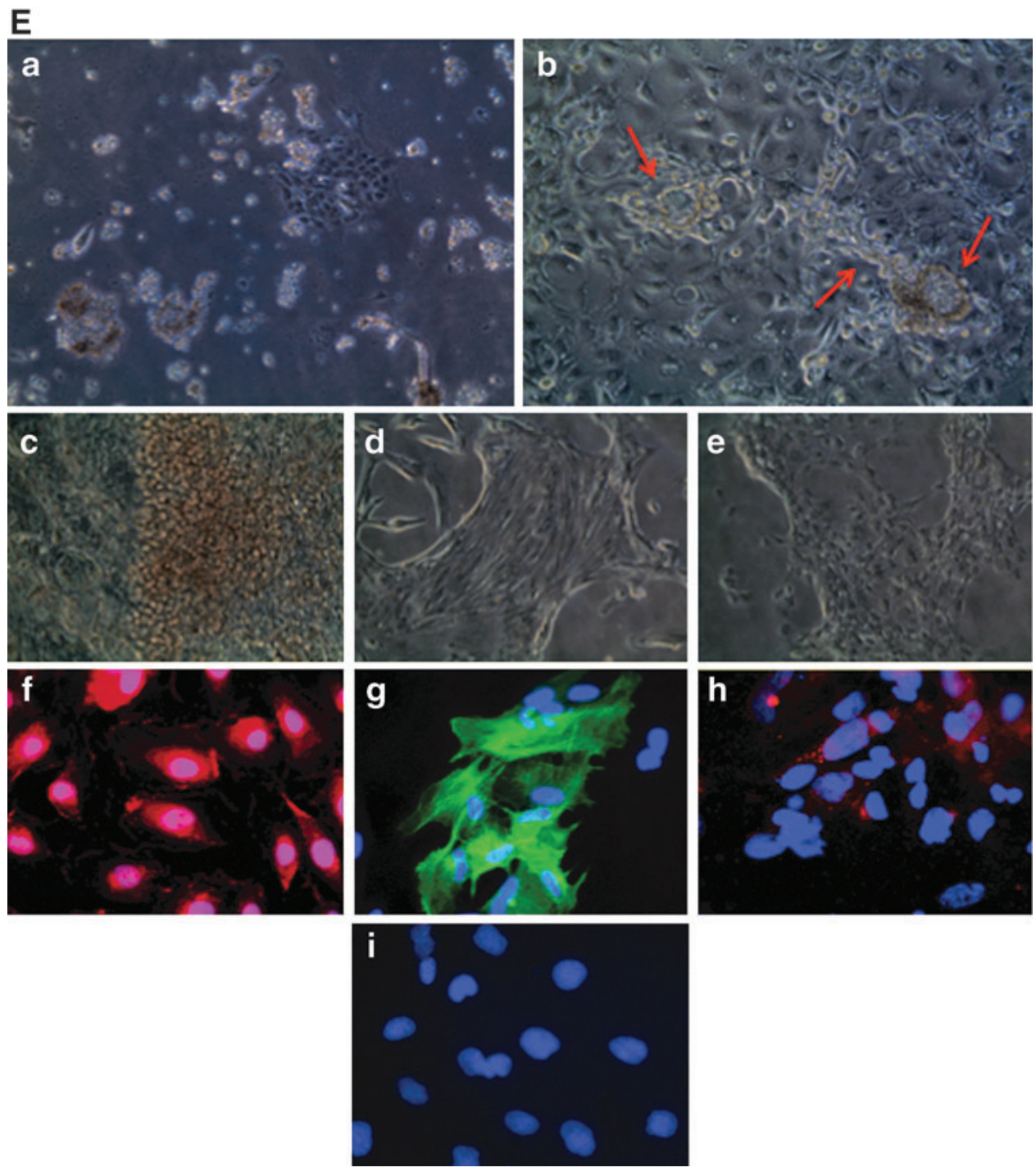

FIG. 3. (Continued).

To investigate the molecular signatures under angioblast differentiation, we profiled the gene expression involved in an angioblast formation as reported previously $[34,35]$. First, RNAs were isolated from EB cultures that underwent differentiation for 5 and 9 days under the angioblast induction medium, together with undifferentiated ESCs and ECs as controls. Figure 3B shows the amplification of 10 transcripts in a real-time PCR system. We found that the expression levels of 2 pluripotent transcription factors had strongly decreased during EB culture by day 5 and day 9, as indicated by the higher Ct values. NANOG was highly expressed in the undifferentiated ESC state $(\mathrm{C} t=25.4)$, but its expression was decreased at day $5(\mathrm{Ct}=31.5)$ and at day $9(\mathrm{Ct}=32.7)$ after induction by ADM culture; similarly, OCT3/4 was highly expressed in ESCs $(\mathrm{Ct}=20.2)$, but became moderately expressed after differentiation for 5 days $(\mathrm{Ct}=25.5)$ and 9 days $(\mathrm{Ct}=26.0)$. Transcription factors that control the formation of angioblasts were upregulated in differentiating EBs. T-brachyury was more highly expressed in differentiating $\mathrm{EBs}(\mathrm{Ct}=25.6$ at day $5 ; \mathrm{Ct}=26.1$ at day 9) than in ESCs $(\mathrm{Ct}=32.0)$; GATA2 showed the same trend in comparing differentiated $\mathrm{EBs}(\mathrm{Ct}=25.6$ at day $5, \mathrm{Ct}=26.1$ at day 9) with
ESCs $(\mathrm{Ct}=34.8)$. Angioblasts generated by the current protocol did not express mature endothelial proteins, such as CD144, TEK, and VWF. CD34 in differentiating EBs at day $5(\mathrm{Ct}=32.5)$ and at day $9(\mathrm{Ct}=31.0)$ was slightly increased in comparison to $\mathrm{ESC}(\mathrm{Ct}=35.5)$. CD31 expression was the highest after 5 days of differentiation $(\mathrm{Ct}=27.6)$, and its expression was lower after 9 days $(C t=31.0)$, similarly to expression of ECs $(C t=29.5)$ and ESCs $(\mathrm{Ct}=31.6)$. KDR, another mesodermal marker, showed upregulation in differentiating EBs (day 5 vs. day 9), but high levels were found in both ESCs and ECs. To validate the expression of key molecules that control mesodermal formation, we disassociated cells from ESCs and EBs at day 5 by enzymatic digestion and cytospun them onto slides; we found that GATA2 was strongly stained in EBs at day 5, while T-brachyury was stained strongly in some cells. KRD positivity was stronger in ESCs than differentiating EBs at day 5 (Fig. 3C).

Second, we investigated cellular surface antigenic expression during the differentiation by flow cytometry analysis. Single cells were prepared from undifferentiated ESCs and from EBs in ADM culture for 3 days and 9 days. We immunostained the cells for CD34, CD31, CD117, CXCR4, 
Table 3. Percent-Positive Cellls of Putative Angioblast-Related Subpopulations in Gated Regions in Fig. 3D

\begin{tabular}{lccc}
\hline Markers & $\begin{array}{c}\text { Pluripotent } \\
\text { cells }\end{array}$ & $\begin{array}{c}\text { 3 Days } \\
\text { differentiation }\end{array}$ & $\begin{array}{c}9 \text { Days } \\
\text { differentiation }\end{array}$ \\
\hline CD31+ & 1.02 & 95.96 & 1.18 \\
CD34+ & 0.27 & 0.65 & 3.39 \\
CD31+ /CD34+ & 0.25 & 0.65 & 1.04 \\
CD117+ & 0.06 & 3.38 & 0.26 \\
CD117+ / & 0.00 & 0.18 & 0.01 \\
CD34+ & & & \\
VEGFR3+ & 0.03 & 0.77 & 0.30 \\
CXCR4+ & 0.00 & 3.94 & 11.58 \\
\hline
\end{tabular}

and VEGFR3. Several populations appeared during the differentiation process as shown in Fig. 3D; the corresponding positivity in percentage is provided in Table 3 . We found that EB culture for 3 days dramatically promoted CD31 expression [95.96\%; Fig. 3D(b)] in comparison with undifferentiated ESCs [1.02\%; Fig. 3D(a)] and EBs obtained after culture for 9 days [1.18\%; Fig. 3D(c)]; CD117-positive cells also peaked at 3 days [Fig. 3D(d-f)]. There were steady increases of CD34-positive cells [from $0.27 \%$ to 3.39\%; Fig. $3 \mathrm{D}(\mathrm{b}, \mathrm{c})]$ and CXCR4-positive cells [0.0\%-11.58\%; Fig. 3D(h, i)] during the differentiation process. The change in VEGFR3 was not obvious [Fig. 3D(h, i)]. A population with coexpressed CD34+/CD31+, but not CD117, appeared at day 9 [1.04\%; Fig. 3D(c, f)]. These results illustrate that EB culture under ADM resulted in the formation of several populations with angioblast characteristics.

Next, we observed the growth of derived angioblasts and documented their potential to differentiate under static culture conditions. After they were harvested, EBs were transferred to collagen-coated plates and cultured under the modified ADM. One day after culture, we observed that suspended cell clusters coexisted with adherent cells [Fig. 3E(a)]. After culture for 7-10 days, we could distinguish 3 distinct types of colonies with different shapes: (1) grapeshaped cell clusters [Fig. 3E(c), reddish hemoglobinized cells] under phase-contrast microscopy that stained positively for CD235a [Fig. 3E(f), in red], an erythrocyte precursor marker; (2) spindle-shaped cells [Fig. 3E(d)] that stained positively for smooth muscle $\alpha$-actin with mature fibers in some cells as well as unassembled protein in other cells [Fig. 3E(g)], indicating a smooth muscle cell origin; and (3) cobblestoneshaped cells [Fig. 3E(e)] that strongly stained for CD34 [Fig. $3 \mathrm{E}(\mathrm{h})]$, indicative of endothelial-like cells. In addition, we observed multiple lumen and capillary structures spreading out in the culture dishes [Fig. 3E(b), indicated by red arrows].

The above data indicated that our angioblast differentiation protocol could generate angioblasts via mesodermal intermediates and that the derived cells demonstrated dual potential to differentiate into hematopoietic and vascular lineages.

\section{Reconstitution of angioblasts derived from ESCs under ex vivo culturing}

To test whether derived angioblasts could function as therapeutic agents in a reparative role, we examined their ability to re-endothelialize blood vessels whose endothelium was removed by enzymatic digestion in the ex vivo bioreactor (Fig. 4). After ex vivo culturing with EGM-2, we took samples of the vessel segment for scanning electron microscopy and immunofluorescence, to assess the fate of the transplanted cells.

Figure 5 shows the evidence of the integration of angioblasts cultured under EGM-2 perfusion on denuded vasculature under ex vivo culture. By using scanning electron microscopy, we demonstrated that ESC-derived angioblasts

A
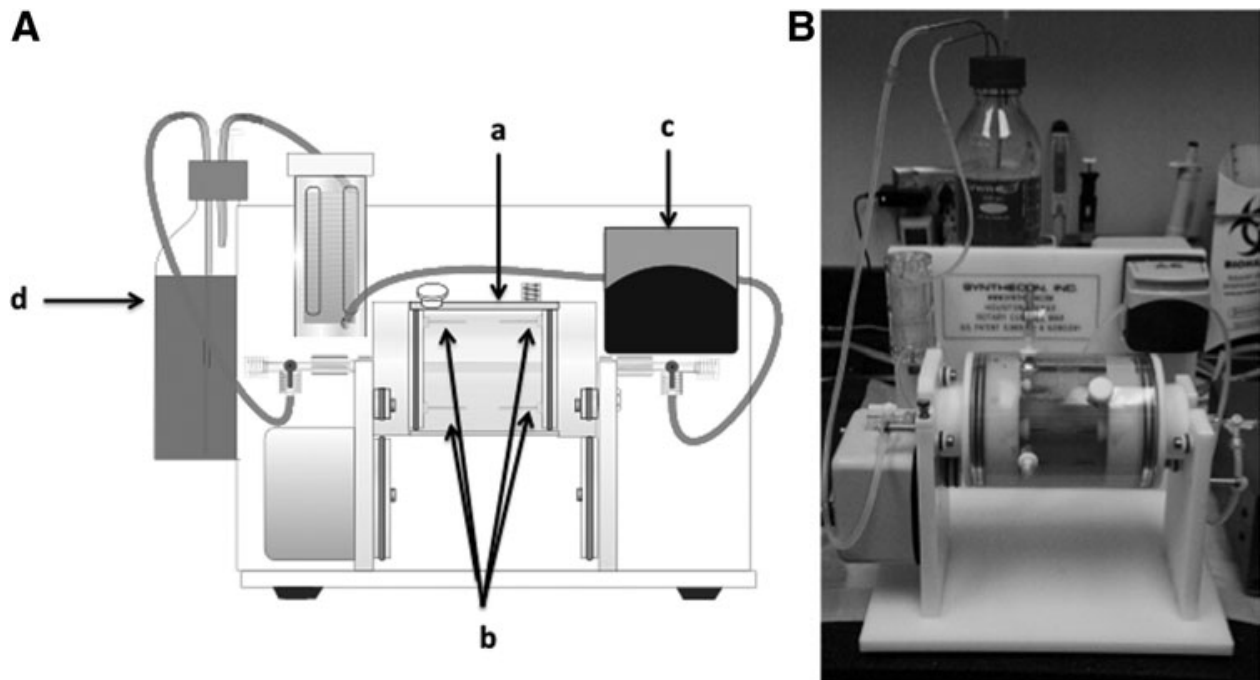

FIG. 4. Ex vivo bioreactor. (A) Diagram of bioreactor for evaluating the reconstitutive ability of derived angioblasts. The bioreactor has 2 parts: a rotary cylinder (a) with 4 stainless steel tubes on both sides (b), and a laminar perfusion system (c) driven by a digital peristaltic pump. The cells to be tested were seeded onto the lumen of the denuded artery, and then the 2 ends of the segment were ligated with plastic tubing to construct a circuit. Endothelial differentiation medium in a reservoir (d) was perfused through the lumen of the vessel using a digital peristaltic pump. The vessel was submerged in medium and placed in an incubator. (B) Photograph of the bioreactor. 

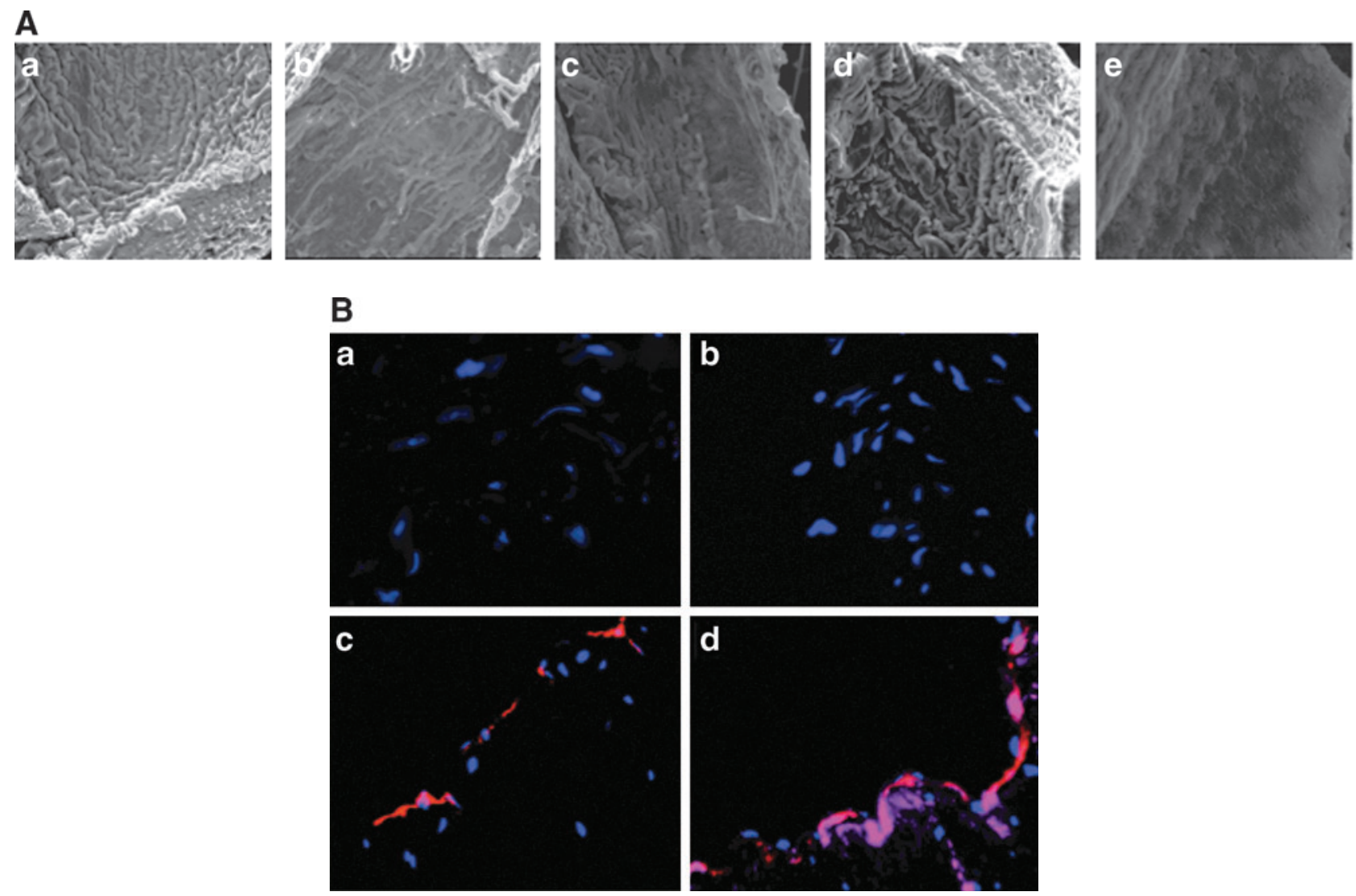

FIG. 5. Reconstitution of angioblast cultures derived from ESCs in ex vivo culture system. (A) Scanning electron microscopy images showing re-endothelialization of denuded endothelium layer by inoculated ESC-derived endothelial progenitor cells. Normal endothelium (a); denuded artery (b); growth status of ESC-derived EPCs 3 days after seeding (c) and 5 days after seeding (d) on denuded blood vessels; vehicle control without cell seeding after 5 days (e). $100 \times$. (B) Attachment and growth of angioblasts on denuded artery surface. When ESC-derived angioblasts are transplanted into an ex vivo culture system, the cells attach, grow, and mature on the interior surface of denuded blood vessels. The transplanted cells marked with CellTracker probe (in red) integrated into the lumen of the denuded vessel surface, thus demonstrating their ability to reconstitute damaged blood vessels $(\mathbf{c}, \mathbf{d})$; the vehicle control group did not show any presence of fluorescence probe (a, b). Prolonged culture of angioblasts for 2 weeks expressed CD31 antigen [in purple (d)], while short-term culture for 5 days (c) did not show CD31 positivity. Nuclei are stained blue with DAPI. $400 \times$. EPC, endothelial progenitor cell.

attached to the extracellular matrix and recovered the denuded surface within 5 days in culture. As indicated in Fig. $5 \mathrm{~A}$, the artery was completely denuded [Fig. $5 \mathrm{~A}(\mathrm{~b})]$ in comparison to the normal artery [Fig. $5 \mathrm{~A}(\mathrm{a})] ; 60 \%-70 \%$ of coverage was obtained after differentiated ESCs began to graft onto the denuded surface after 3 days in perfusion culture [Fig. 5A(c)], coverage of the luminal surface became nearly complete after 5 days in perfusion culture [Fig. 5A(d)], and no cells were seen in the vehicle control group [Fig. $5 \mathrm{~A}(\mathrm{e})]$. Finally, we investigated whether transplanted derived angioblasts could functionally reconstitute the damaged endothelium. After ex vivo culturing for approximately 2 weeks, a $0.5-0.7-\mathrm{cm}$ segment was fixed, embedded, and sectioned longitudinally into $10-\mu \mathrm{m}$-thick serial sections and whole-mount immunostaining was performed to assess the fate of the transplanted cells. Figure 5B shows cellular images acquired from serial sections from a representative ex vivo sample. Angioblasts labeled with CellTracker (in red) were found to integrate and recover the denuded surface under ex vivo culture; and integrated cells expressed CD31 (in purple) after prolonged culture [Fig. $5 \mathrm{~A}(\mathrm{~d})]$ by comparison to short-term 5-day perfusion [Fig. 5A(c)]; CD31 is an antigenic marker for ECs lining the lumen of blood vessels. This result indicated that the transplanted ESC-derived angioblasts possessed reparative ability and were able to repair the injured vascular tissue.

\section{Discussion}

The development of stem cell-based therapies and their application for regenerative medicine have become more dependent on animal models [36]. Results from those models, whether amphibians or mammals, have contributed to a better understanding of the mechanisms underlying cell therapy. However, large animal models have demonstrated a better suitability for translation to humans, since a substantial body of evidence has clearly demonstrated differences between human and mouse ESCs [37-39]. A large Old World nonhuman primate, the baboon, has an advantage over other large models because of the high level of similarity of its physiological characteristics to those of humans $[13,40-42]$. The results of the present study suggest that 
baboon ESCs represent a new research tool that is highly relevant for stem cell therapy in human, thus contributing to developing clinical application of stem cell therapies.

Our results indicate that baboon ESC differentiation toward the endothelial lineage resembles the process in humans. In human ESCs, derivation of endothelial lineage cells appears to undergo the cascade of molecular events leading to the commitment to mesoderm and the formation of hemangioblasts [40-43]. When baboon ESCs were cultured as EBs in culture with vasculogenic factors (VEGF, FGF, and BMP-4), we observed upregulated expression of mesodermal markers and downregulated pluripotent markers (Fig. 3B, C), which are very similar to the results seen with human ESCs. We also observed that angioblasts derived from baboon ESCs by EB formation, a process that partially mimics the spatial organization of cells in embryo, could generate both adherent and nonadherent cells [Fig. 3E(a)] under in vitro culturing, and that some adherent colonies expressed endothelial markers [Fig. 3E(e)]. This observation is consistent with the results of Zambidis et al., who found that hematopoietic differentiation of human ESCs generated 2 types of colonies at the early stage of differentiation [44]. They described that nonadherent cells expressed CD45 and gave rise to hematopoietic colonies, and that adherent cells differentiated into ECs. We also confirmed that baboon angioblasts generated using the current protocol exhibited markers in a time-dependent manner (Fig. 3D) that closely recapitulates endothelial differentiation in vivo during embryonic development [45,46], and shared common phenotypic characteristics with human ESCs $[40,47,48]$. More interestingly, the kinetics and efficiency of CD34+/CD31+ cells in baboons were very close to those reported for human ESCs $[40,47,48]$. When angioblast cultures were grown in a monolayer, they have the potential for multiple lineage differentiation. As shown in Fig. $3 \mathrm{E}(\mathrm{a}-\mathrm{h})$, baboon angioblast cultures are able to differentiate into hematopoietic and vascular lineages under current conditions; these data were consistent with previous findings that dual potential hemangioblasts exist during human ESC differentiation $[33,48,49]$. Although there were differences in the kinetics of hematopoietic commitment occurrence, both human and baboon ESCs could be derived into multiple cell lineages, depending on the culture conditions. One particular similarity is that both human and baboon undifferentiated ESCs express KDR (Fig. 3B, C), whereas they expressed CD34 only when they underwent differentiation toward angioblasts [Fig. 3D $(\mathrm{a}-\mathrm{c}, \mathrm{d}-\mathrm{f})][47,50]$. However, we noticed that 2 CD34+ populations were expressed with high or low intensity during baboon ESC differentiation toward ECs, which has not been reported in human ESCs, as shown in Fig. $3 \mathrm{D}(\mathrm{c}, \mathrm{f})$; further studies are required to determine whether human ESCs, if treated by our established procedure, give rise to the same populations. Collectively, the above findings suggest that the differentiation of baboon ESCs may maximally represent the molecular and cellular events that regulate embryonic EC fate in human stem cells.

We have demonstrated that differentiated baboon ESCs possess reparative function and are able to recover damaged arterial tissues. ECs derived from human ESCs are capable of forming vascular-like structures [50], having similar gene expression patterns to those of mature ECs [51], and improving blood circulation $[32,48]$. To demonstrate the func- tionalities of derived cells in the baboon, we tested the endothelium-forming ability of ESC-derived angioblasts in an ex vivo culture system. Since it remains unclear which characteristics are essential for angioblasts to form the endothelium, we transplanted heterogeneous angioblast cultures after they were specified under monolayer conditions, which allowed derived cells grow maximally in ex vivo culture conditions (data not shown). Our data from scanning electron microscopy demonstrated that transplanted ESCderived angioblasts attach to the interior lumen of a denuded blood vessel within 5 days; prolonged culturing allowed the attached cells to integrate the damaged vessel surface and to express the endothelial specific antigen CD31, thus reconstituting the vessel.

Using the baboon as a research model enables us to conduct experiments or manipulations that are impossible to perform in humans. There is increasing evidence that stem cells are capable of differentiating and proliferating if only they reside in their appropriate niches [52,53]; the regulation, survival, proliferation, and differentiation of stem cells is ultimately determined by a combination of factors intrinsic to the stem cells themselves and extrinsic signals received from the microenvironment [19-24]. Organ-specific regulators, other as-yet-unrecongnized factors and matrix components are essential for functional incorporation of transplanted cells [18]. Since our ability to bring pluripotent stem cell biology into cell-based therapy will depend largely on the effectiveness of the derived cells, functional and therapeutic ESC-derived regenerative cells cannot be correctly identified without considering their cellular and molecular interactions with their environmental components. In this study, we designed a novel approach to identify functional and highly regenerative cells for stem cell therapy based on this principle. We placed the committed ESCderived angioblasts in a naturally damaged environment that provides the appropriate combination of their surroundings and allowed them direct contact with signaling molecules to induce and support lineage-specific differentiation, thus facilitating their incorporation and maturation. We confirmed that ESC-derived angioblasts have the potential to replace the endothelium; the baboon is the most suitable model to perform this investigation because of the availability of the biopsy tissues.

While many ESC-derived cells appear to be attractive therapeutic options for treating vascular injury, standard and robust in vitro and in vivo investigations of the biology of these cells are needed to identify those that will be the most amenable to therapeutic application. Using our model system, we can discriminate the potential cell candidates that are able and ready to regenerate the damaged endothelium from those are not, reproducibly. To our knowledge, this is the first objective and controlled system for evaluating the functionalities of ESC-derived cells; it is impractical to assess the therapeutic value of potential candidates in this manner because human arteries are not available for the ex vivo assay system on a day-to-day basis. Although in this study, we used a heterogeneous population to demonstrate their ability to reconstitute damaged blood vessels, we are aware that phenotype-defined cell populations will be required for optimal cell therapy. We plan to use our bioassay system to screen a wide spectrum of purified populations that are derived from undifferentiated cells to determine which cells are 
optimal therapeutic candidates; we also plan to develop an expansion protocol to induce differentiation of pluripotent stem cells into readily transplantable cells to promote tissue repair, restoration, and regeneration.

In conclusion, we have successfully established a protocol to differentiate baboon ESCs into endothelial lineage cells and confirmed their therapeutic functionalities by a bioassay system in a preclinical setting. With the advent of stem cell processing technology and its application in medicine, generating functional endothelial precursors for rejuvenating blood vessels will form a cornerstone for the prevention and treatment of CVD.

\section{Acknowledgments}

This work was supported by the NIH grant P01 HL028972 and P51 RR083986; by the Voelcker Foundation SFBR094206; and by The Texas Biomedical Research Institute's Founder's Council. The baboons used for this study were housed in facilities contracted with support from Research Facilities Improvement Grant Number C06 RR015456. The authors thank Janet Barber and Tiffany Heard for their technical assistance in baboon ESC culture and maintenance; Allen Ford for his assistance in isolating endothelial cells from blood vessels; Jennifer Meehan for her assistance in manuscript preparation.

\section{Author Disclosure Statement}

No competing financial interests exist.

\section{References}

1. Roger VL, AS Go, DM Lloyd-Jones, RJ Adams, JD Berry, TM Brown, MR Carnethon, S Dai, G de Simone, et al. (2011). Heart disease and stroke statistics-2011 update: a report from the American Heart Association. Circulation 123: e18-e209.

2. Abbott JD and FJ Giordano. (2003). Stem cells and cardiovascular disease. J Nucl Cardiol 10:403-412.

3. Ballard VL and JM Edelberg. (2007). Stem cells and the regeneration of the aging cardiovascular system. Circ Res 100:1116-1127.

4. Mitka M. (2011). Statin therapy in primary CVD prevention remains a hot-button topic for some. JAMA 306:2077-2078.

5. Libby P, PM Ridker and GK Hansson. (2011). Progress and challenges in translating the biology of atherosclerosis. Nature 473:317-325.

6. Erbs S, A Linke, V Adams, K Lenk, H Thiele, KW Diederich, F Emmrich, R Kluge, K Kendziorra, et al. (2005). Transplantation of blood-derived progenitor cells after recanalization of chronic coronary artery occlusion: first randomized and placebo-controlled study. Circ Res 97:756-762.

7. Napoli C, T Hayashi, F Cacciatore, A Casamassimi, C Casini, M Al-Omran and LJ Ignarro. (2011). Endothelial progenitor cells as therapeutic agents in the microcirculation: an update. Atherosclerosis 215:9-22.

8. Critser PJ and MC Yoder. (2010). Endothelial colony-forming cell role in neoangiogenesis and tissue repair. Curr Opin Organ Transplant 15:68-72.

9. Iacobas I, A Vats and KK Hirschi. (2010). Vascular potential of human pluripotent stem cells. Arterioscler Thromb Vasc Biol 30:1110-1117.
10. Brons IG, LE Smithers, MW Trotter, P Rugg-Gunn, B Sun, SM Chuva de Sousa Lopes, SK Howlett, A Clarkson, L Ahrlund-Richter, RA Pedersen and L Vallier. (2007). Derivation of pluripotent epiblast stem cells from mammalian embryos. Nature 448:191-195.

11. Jakobsson L, J Kreuger and L Claesson-Welsh. (2007). Building blood vessels-stem cell models in vascular biology. J Cell Biol 177:751-755.

12. Behr L, M Hekmati, A Lucchini, K Houcinet, AM Faussat, $N$ Borenstein, LH Noel, M Lelievre-Pegorier and K Laborde. (2009). Evaluation of the effect of autologous mesenchymal stem cell injection in a large-animal model of bilateral kidney ischaemia reperfusion injury. Cell Prolif 42:284-297.

13. Ben-Yehudah A, CA Easley 4th, BP Hermann, C Castro, C Simerly, KE Orwig, S Mitalipov and G Schatten. (2010). Systems biology discoveries using non-human primate pluripotent stem and germ cells: novel gene and genomic imprinting interactions as well as unique expression patterns. Stem Cell Res Ther 1:24.

14. Wagner JL and R Storb. (1996). Preclinical large animal models for hematopoietic stem cell transplantation. Curr Opin Hematol 3:410-415.

15. Schatten G and S Mitalipov. (2009). Developmental biology: transgenic primate offspring. Nature 459:515-516.

16. Hematti P, P Obrtlikova and DS Kaufman. (2005). Nonhuman primate embryonic stem cells as a preclinical model for hematopoietic and vascular repair. Exp Hematol 33:980-986.

17. Trounson A and ND Dewitt. (2012). Stem cell biology: towards the reality of cell therapeutics. Nat Cell Biol 14:331.

18. Rafii S and D Lyden. (2003). Therapeutic stem and progenitor cell transplantation for organ vascularization and regeneration. Nat Med 9:702-712.

19. Garlanda C and E Dejana. (1997). Heterogeneity of endothelial cells. Specific markers. Arterioscler Thromb Vasc Biol 17:1193-1202.

20. Adamo L, O Naveiras, PL Wenzel, S McKinney-Freeman, PJ Mack, J Gracia-Sancho, A Suchy-Dicey, M Yoshimoto, MW Lensch, et al. (2009). Biomechanical forces promote embryonic haematopoiesis. Nature 459:1131-1135.

21. Shannon JM, LD Nielsen, SA Gebb and SH Randell. (1998). Mesenchyme specifies epithelial differentiation in reciprocal recombinants of embryonic lung and trachea. Dev Dyn 212: 482-494.

22. De Val S and BL Black. (2009). Transcriptional control of endothelial cell development. Dev Cell 16:180-195.

23. Noghero A, F Bussolino and A Gualandris. (2010). Role of the microenvironment in the specification of endothelial progenitors derived from embryonic stem cells. Microvasc Res 79:178-183.

24. Noghero A, M Arese, F Bussolino and A Gualandris. (2011). Mature endothelium and neurons are simultaneously derived from embryonic stem cells by 2D in vitro culture system. J Cell Mol Med 15:2200-2215.

25. Resende LP and DL Jones. (2012). Local signaling within stem cell niches: insights from Drosophila. Curr Opin Cell Biol 24:225-231.

26. Mitalipov S, HC Kuo, J Byrne, L Clepper, L Meisner, J Johnson, R Zeier and D Wolf. (2006). Isolation and characterization of novel rhesus monkey embryonic stem cell lines. Stem Cells 24:2177-2186.

27. Navara CS, C Redinger, J Mich-Basso, S Oliver, A BenYehudah, C Castro and C Simerly. (2007). Derivation and characterization of nonhuman primate embryonic stem cells. Curr Protoc Stem Cell Biol Chapter 1:Unit 1A.1. 
28. Simerly CR, CS Navara, CA Castro, JC Turpin, CJ Redinger, JD Mich-Basso, ES Jacoby, KJ Grund, DA McFarland, et al. (2009). Establishment and characterization of baboon embryonic stem cell lines: an Old World Primate model for regeneration and transplantation research. Stem Cell Res 2:178-187.

29. Ingram DA, LE Mead, H Tanaka, V Meade, A Fenoglio, K Mortell, K Pollok, MJ Ferkowicz, D Gilley and MC Yoder. (2004). Identification of a novel hierarchy of endothelial progenitor cells using human peripheral and umbilical cord blood. Blood 104:2752-2760.

30. Li Z, KD Wilson, B Smith, DL Kraft, F Jia, M Huang, X Xie, RC Robbins, SS Gambhir, IL Weissman and JC Wu. (2009). Functional and transcriptional characterization of human embryonic stem cell-derived endothelial cells for treatment of myocardial infarction. PLoS One 4:e8443.

31. Wang L, L Li, F Shojaei, K Levac, C Cerdan, P Menendez, T Martin, A Rouleau and M Bhatia. (2004). Endothelial and hematopoietic cell fate of human embryonic stem cells originates from primitive endothelium with hemangioblastic properties. Immunity 21:31-41.

32. Ferreira LS, S Gerecht, HF Shieh, N Watson, MA Rupnick, SM Dallabrida, G Vunjak-Novakovic and R Langer. (2007). Vascular progenitor cells isolated from human embryonic stem cells give rise to endothelial and smooth muscle like cells and form vascular networks in vivo. Circ Res 101:286-294.

33. Hill KL, P Obrtlikova, DF Alvarez, JA King, SA Keirstead, JR Allred and DS Kaufman. (2010). Human embryonic stem cell-derived vascular progenitor cells capable of endothelial and smooth muscle cell function. Exp Hematol 38:246257.e1.

34. Coultas L, K Chawengsaksophak and J Rossant. (2005). Endothelial cells and VEGF in vascular development. Nature 438:937-945.

35. Chiang PM and PC Wong. (2011). Differentiation of an embryonic stem cell to hemogenic endothelium by defined factors: essential role of bone morphogenetic protein 4 . Development 138:2833-2843.

36. Steindler DA. (2007). Stem cells, regenerative medicine, and animal models of disease. ILAR J 48:323-338.

37. Thomson JA, J Itskovitz-Eldor, SS Shapiro, MA Waknitz, JJ Swiergiel, VS Marshall and JM Jones. (1998). Embryonic stem cell lines derived from human blastocysts. Science 282:1145-1147.

38. Ludwig TE, ME Levenstein, JM Jones, WT Berggren, ER Mitchen, JL Frane, LJ Crandall, CA Daigh, KR Conard, et al. (2006). Derivation of human embryonic stem cells in defined conditions. Nat Biotechnol 24:185-187.

39. Dinsmore JH and N Dib. (2008). Stem cells and cardiac repair: a critical analysis. J Cardiovasc Transl Res 1:41-54.

40. Bai H and ZZ Wang. (2008). Directing human embryonic stem cells to generate vascular progenitor cells. Gene Ther 15:89-95.

41. Jin SW and C Patterson. (2009). The opening act: vasculogenesis and the origins of circulation. Arterioscler Thromb Vasc Biol 29:623-629.

42. Bautch VL. (2011). Stem cells and the vasculature. Nat Med 17:1437-1443.
43. Lacaud G, G Keller and V Kouskoff. (2004). Tracking mesoderm formation and specification to the hemangioblast in vitro. Trends Cardiovasc Med 14:314-317.

44. Zambidis ET, B Peault, TS Park, F Bunz and CI Civin. (2005). Hematopoietic differentiation of human embryonic stem cells progresses through sequential hematoendothelial, primitive, and definitive stages resembling human yolk sac development. Blood 106:860-870.

45. Vittet D, MH Prandini, R Berthier, A Schweitzer, H MartinSisteron, G Uzan and E Dejana. (1996). Embryonic stem cells differentiate in vitro to endothelial cells through successive maturation steps. Blood 88:3424-3431.

46. Feraud O, Y Cao and D Vittet. (2001). Embryonic stem cellderived embryoid bodies development in collagen gels recapitulates sprouting angiogenesis. Lab Invest 81:1669-1681.

47. Kennedy M, SL D'Souza, M Lynch-Kattman, S Schwantz and G Keller. (2007). Development of the hemangioblast defines the onset of hematopoiesis in human ES cell differentiation cultures. Blood 109:2679-2687.

48. Wang ZZ, P Au, T Chen, Y Shao, LM Daheron, H Bai, M Arzigian, D Fukumura, RK Jain and DT Scadden. (2007). Endothelial cells derived from human embryonic stem cells form durable blood vessels in vivo. Nat Biotechnol 25: 317-318.

49. Lu SJ, Q Feng, S Caballero, Y Chen, MA Moore, MB Grant and R Lanza. (2007). Generation of functional hemangioblasts from human embryonic stem cells. Nat Methods 4:501-509.

50. Levenberg S, J Zoldan, Y Basevitch and R Langer. (2007). Endothelial potential of human embryonic stem cells. Blood 110:806-814.

51. Nourse MB, DE Halpin, M Scatena, DJ Mortisen, NL Tulloch, KD Hauch, B Torok-Storb, BD Ratner, L Pabon and CE Murry. (2010). VEGF induces differentiation of functional endothelium from human embryonic stem cells: implications for tissue engineering. Arterioscler Thromb Vasc Biol 30:80-89.

52. Tan A, BE Sumpio, S Lee and AM Seifalian. (2010). The implications of human stem cell differentiation to endothelial cell via fluid shear stress in cardiovascular regenerative medicine: a review. Curr Pharm Des 16:3848-3861.

53. Zapata AG, D Alfaro and J Garcia-Ceca. (2012). Biology of stem cells: the role of microenvironments. Adv Exp Med Biol 741:135-151.

Address correspondence to: Dr. Qiang Shi Southwest National Primate Research Center Texas Biomedical Research Institute P.O. Box 760549

San Antonio, TX 78245-0549

E-mail: qshi@txbiomedgenetics.org

Received for publication June 8, 2012

Accepted after revision August 29, 2012

Prepublished on Liebert Instant Online August 30, 2012 